\title{
Current management of juvenile dermatomyositis in Germany and Austria: an online survey of pediatric rheumatologists and pediatric neurologists
}

\author{
Claas H. Hinze ${ }^{1 *} \mathbb{D}$, Fabian Speth ${ }^{2,3}$, Prasad T. Oommen ${ }^{4}$ and Johannes-Peter Haas ${ }^{5}$
}

\begin{abstract}
Background: Juvenile Dermatomyositis (JDM) is a rare pediatric autoimmune disease with broad variations of the individual course. Data on the optimal management are mostly lacking. Currently treatment decisions are often based on experts' opinions. In order to develop consensus-based treatment strategies for JDM in Germany a survey was pursued to analyze the current clinical practice.

Methods: An online survey addressing all members of the Society for Pediatric Rheumatology (GKJR) in Germany and Austria and pediatric neurologists with expertise in JDM was performed in February/March of 2016. The questionnaire consisted of 5 case scenarios including diagnostic criteria, treatment of moderate, severe and refractory JDM, using either multiple choice or a 5-point Likert scale. Basic descriptive statistics were used to analyze the findings.

Results: The survey was completed by 60 pediatric rheumatologists and 7 pediatric neurologists experienced in the management of JDM. Typical findings allowing a diagnosis were considered to be: typical skin changes, proximal muscle weakness, MRl findings, elevated muscle enzymes, nailfold capillary changes, presence of calcinosis and muscle biopsy. Regarding induction treatment of moderate/severe JDM: 59\%/74\% opted for intermittent intravenous methylprednisolone (IVMP) pulse therapy, and 21\%/40\% for conventional high-dose oral glucocorticoids. Methotrexate (MTX) was the preferred disease-modifying conventional anti-rheumatic drug (CDMARD) for moderate and severe JDM. Regarding the management of refractory moderate or severe JDM, intravenous immune globulins, mycophenolate mofetil and rituximab were preferred treatment options.

Conclusion: There is consensus about the diagnosis of JDM strongly supported by classic clinical and MRI findings. There is great variety in the treatment of JDM in Germany regarding both induction and maintenance therapy. The development of consensus-based treatment strategies for JDM based on harmonization of current clinical practice is essential in order to allow comparative effectiveness research in the future.
\end{abstract}

Keywords: Dermatomyositis, Surveys and questionnaires, Practice patterns, Physicians, Glucocorticoids, Methotrexate, Antirheumatic agents, Immunoglobulins, Intravenous

\footnotetext{
* Correspondence: claas.hinze@ukmuenster.de

${ }^{1}$ Department of Pediatric Rheumatology and Immunology, University

Hospital Münster, Albert-Schweitzer-Campus 1, Building D3, 48149 Münster,

Germany

Full list of author information is available at the end of the article
}

(c) The Author(s). 2018 Open Access This article is distributed under the terms of the Creative Commons Attribution 4.0 International License (http://creativecommons.org/licenses/by/4.0/), which permits unrestricted use, distribution, and reproduction in any medium, provided you give appropriate credit to the original author(s) and the source, provide a link to the Creative Commons license, and indicate if changes were made. The Creative Commons Public Domain Dedication waiver (http://creativecommons.org/publicdomain/zero/1.0/) applies to the data made available in this article, unless otherwise stated. 


\section{Background}

Juvenile dermatomyositis (JDM) is the most common inflammatory myopathy of childhood [1]. Even though it is a rare condition, it is still a major cause of morbidity and mortality among patients with pediatric rheumatic diseases $[2,3]$. The Bohan-Peter diagnostic criteria for dermatomyositis (DM) exist for more than 40 years, and those criteria are also often used to diagnose JDM [4]. Several other diagnostic modalities are employed by physicians to diagnose and monitor JDM, including for example, imaging studies and various laboratory markers [5]. Surveys performed in North America demonstrated a high variability in the management of JDM [6]. A European initiative resulted in international consensus-based recommendations and treatment protocols $[7,8]$. Currently, it is unclear if practice patterns in Germany vary from those in North America or other countries, so that additional data are desirable.

The PRO-KIND (PROjekte zur Klassifikation, Überwachung und Therapie in der KINDerrheumatologie; projects for the classification, monitoring and therapy in pediatric rheumatology) initiative is a sub-committee of the Society for Pediatric Rheumatology (Gesellschaft für Kinder- und Jugendrheumatologie, GKJR) and aims to define consensus-based protocols to harmonize diagnostic and treatment approaches in Germany. International efforts are currently made to establish disease specific registries for pediatric patients with inflammatory myopathies $[9,10]$. However, a German registry sufficiently recording clinical practice and treatment of JDM does not currently exist.

The goal of the PRO-KIND working group on JDM was to identify current practice patterns in Germany via an online survey among pediatric rheumatologists and pediatric neurologists and subsequently to harmonize identified patterns. This manuscript reports on a survey concerning the current practice in diagnosing and managing JDM in Germany.

\section{Methods}

\section{Study population}

The online survey was addressed to all 229 members of the German Society of Pediatric Rheumatology (GKJR) via e-mail with personal invitations to the address available via the society's membership database. In addition, pediatric neurologists were invited via the website of the German Society for Pediatric Neurology (GNP).

\section{Instrument}

It was estimated that a survey designed to take 30$45 \mathrm{~min}$ to complete would be acceptable to participants in the survey. The authors C.H., F.S. and P.O. opted to develop a survey consisting of 5 case scenarios (23 questions) with the option to extend the survey for an additional case scenario addressing the issue of dystrophic calcification (9 questions). The survey specifically addressed (1) initial diagnostic measures taken in a patient with probable JDM, making the diagnosis of moderate JDM and initial treatment steps (10 questions), (2) maintenance treatment in patients with moderate JDM (6 questions), (3) treatment of refractory moderate JDM (3 questions), (4) treatment of glucocorticoid-dependent moderate JDM (1 question), (5) initial treatment of severe JDM and treatment of refractory severe JDM (3 questions), and, optionally, (6) management of dystrophic calcification (9 questions) (Additional file 1). Some of the questions were multiple choice questions, "select all that apply" questions (both with the option to add free text) and some required grading items on a Likert scale. The part of the survey addressing the management of dystrophic calcification eventually was excluded from this manuscript because of the lower number of participants $(n=49)$ in that part of the survey.

\section{Survey administration}

The survey was conducted between February 2, 2016, and March 15, 2016 using the web-based program Survey Monkey (SurveyMonkey Inc.; San Mateo, California, USA; www.surveymonkey.com). A link to the survey was sent out to the pediatric rheumatologists on February 2, 2016, and a link was posted on the Society for Pediatric Neurology's website on February 15, 2016. A reminder e-mail was sent out to pediatric rheumatologists who had not opened the survey two weeks prior to closing the survey.

\section{Data on registered patients with JDM in Germany}

The National Pediatric Rheumatic Disease Database ("Kerndokumentation rheumakranker Kinder und Jugendlicher"), a registry which annually collects cross-sectional data on pediatric rheumatic disease in Germany, was queried regarding the number of patients with JDM and the number of centers reporting patients with JDM between 2012 and 2016.

\section{Analysis of responses}

Basic descriptive statistics were performed to summarize the responses with Microsoft Excel (Redmond, Washington, USA). Differences in the responses pediatric rheumatologists and neurologists regarding categorical variables were analyzed via chi-square test.

\section{Results}

\section{Characteristics of the study population}

Sixty GKJR members completed the survey for a response rate of $26.2 \%(60 / 229)$, as well as 7 pediatric neurologists (response rate not calculable). According to the National Pediatric Rheumatic Disease Database, 50 pediatric 
rheumatology centers in Germany have reported patients with JDM to the database between 2012 and 2016 (2012: 77 patients, 2013: 89 patients, 2014: 108 patients, 2015: 121 patients, 2016: 127 patients) of which at least 29 centers, including the top-enrolling centers, were represented within this survey. Of the 60 GKJR members, 57 (85\%) were practicing pediatric rheumatologists, and 3 (4\%) were either fellows in pediatric rheumatology or general pediatricians with a special interest in JDM. Regarding the type of practice, $30(45 \%)$ worked in a university hospital setting, $31(46 \%)$ in a non-university hospital setting, and 4 (6\%) in private practice. All survey participants had treated patients with JDM; two (3\%) had treated more than 50, 14 (21\%) between 21 and 50, 19 (28\%) between 11 and 20, and 31 between 1 and 10 JDM patients. Fifty-eight participants $(87 \%)$ were currently managing JDM patients.

\section{Preferred diagnostic tools in patients with probable JDM} Participants were queried to indicated which type of diagnostic tools they would apply in every patient with probable JDM. Diagnostic studies across multiple categories were inquired about, including clinical scores, laboratory testing, imaging studies, apparatus-based studies (e.g. pulmonary function testing), and consultation of other subspecialities (Table 1). The following diagnostics were suggested by at least $75 \%$ of participants: Erythrocyte sedimentation rate, glutamate oxaloacetate transaminase (GOT)/aspartate aminotransferase (AST), glutamate pyruvate transaminase (GPT)/alanine aminotransferase (ALT), creatine kinase (CK), lactate dehydrogenase (LDH), antinuclear antibodies (ANA), complete blood count $(\mathrm{CBC})$ with differential count, C-reactive protein (CRP), urea, creatinine, immune globulin (Ig) G/IgA/IgM, electrocardiography (ECG), pulmonary function testing, echocardiography and muscle magnetic resonance imaging (MRI). There were some differences between pediatric rheumatologists and pediatric neurologist concerning the diagnostic testing rendered (chi square $p<0.05$ ): Ig levels (pediatric rheumatologists $85 \%$ vs. pediatric neurologists 43\%), anti-extractable nuclear antigen (ENA) antibodies (78\% vs. $29 \%$ ), capillary microscopy ( $70 \%$ vs. $14 \%)$, abdominal ultrasound (65\% vs. $0 \%$ ), serologic testing for infectious agents (42\% vs. $0 \%$ ) and childhood myositis assessment scale (CMAS) testing ( $83 \%$ vs. 0\%), and, in contrast manual muscle testing (13\% vs. $57 \%)$ and muscle biopsy (13\% vs. $57 \%)$.

\section{Establishing a diagnosis of JDM}

Since clinical symptoms and signs of JDM may vary, participants were asked to rate individual findings regarding their importance in establishing a diagnosis of JDM in clinical practice. Typical skin changes, proximal muscle weakness, typical MRI findings and elevated muscle enzymes were deemed to be most the important features (Fig. 1).

\section{Experience with validated measures of disease activity or damage}

The majority of participants were familiar with several disease activity measures, including the CMAS (91\%), the physician global score (87\%), the childhood health

Table 1 Preferred testing in patients with probable juvenile dermatomyositis

\begin{tabular}{|c|c|c|}
\hline Diagnostic categories & $\begin{array}{l}\text { Proportion of participants } \\
\text { supporting testing }\end{array}$ & Specific diagnostic tests \\
\hline \multirow[t]{3}{*}{ Laboratory diagnostics } & $>75 \%$ of participants ${ }^{a}$ & $\begin{array}{l}\text { Erythrocyte sedimentation rate, GOT/AST, GPT/ALT, CK, LDH, ANA, CBC with differential } \\
\text { count, CRP, BUN/creatinine, IgG/lgA/lgM }\end{array}$ \\
\hline & $50-75 \%$ of participants ${ }^{a}$ & $\begin{array}{l}\text { C3 and C4, myositis blot, ENA panel, VWF antigen, total protein, ferritin, thyrotropin, } \\
\text { uric acid, aldolase, rheumatoid factor and CCP antibody }\end{array}$ \\
\hline & $<50 \%$ of participants ${ }^{a}$ & $\begin{array}{l}\text { Albumin, } 25-\mathrm{OH} \text { vitamin } \mathrm{D} \text {, extended myositis blot (including anti-NXP2, -TIF1gamma, } \\
\text {-MDA5), serologic testing for certain infections, cardiac-specific troponin, SPEP, NT } \\
\text { pro-BNP, fecal calprotectin, serum neopterin, 1,25 (OH)2 vitamin D, tTG-IgA, lymphocyte } \\
\text { subpopulations, stool occult blood }\end{array}$ \\
\hline \multirow{3}{*}{$\begin{array}{l}\text { Apparatus-based diagnostics or } \\
\text { interventions }\end{array}$} & $>75 \%$ of participants ${ }^{a}$ & ECG, pulmonary function testing, echocardiography, muscle MRI \\
\hline & $50-75 \%$ of participants ${ }^{a}$ & muscle ultrasound, nailfold capillaroscopy, abdominal ultrasound \\
\hline & $<50 \%$ of participants ${ }^{a}$ & Chest radiograph, EMG, muscle biopsy, swallow study, chest $C T$ \\
\hline \multirow{3}{*}{$\begin{array}{l}\text { Juvenile dermatomyositis-specific } \\
\text { clinical scores or subspecialty } \\
\text { consultations }\end{array}$} & $>75 \%$ of participants ${ }^{a}$ & N/A \\
\hline & $50-75 \%$ of participants ${ }^{a}$ & Childhood myositis assessment scale (CMAS) \\
\hline & $<50 \%$ of participants ${ }^{a}$ & $\begin{array}{l}\text { Disease activity score, dermatology consultation, manual muscle testing (MMT)-8, } \\
\text { neurology consultation }\end{array}$ \\
\hline
\end{tabular}

Abbreviations: $A N A$ antinuclear antibodies, $A L T$ alanine aminotransferase, $A S T$ aspartate aminotransferase, $B U N$ blood urea nitrogen, $C B C$ complete blood count, $C C P$ cyclic citrullinated peptide, $C K$ creatine kinase, CRP C-reactive protein, ECG electrocardiogram, EMG electromyogram, ENA extractable nuclear antigen, GOT glutamate oxaloacetate transaminase, GPT glutamate pyruvate transaminase, $l g$ immunoglobulin, $L D H$ lactate dehydrogenase, MRI magnetic resonance imaging, NT pro-BNP N-terminal pro-brain natriuretic peptide, SPEP serum protein electrophoresis, $t T G$ tissue transglutaminase, $v W F$ von Willebrand factor atests are listed in order of descending frequency 


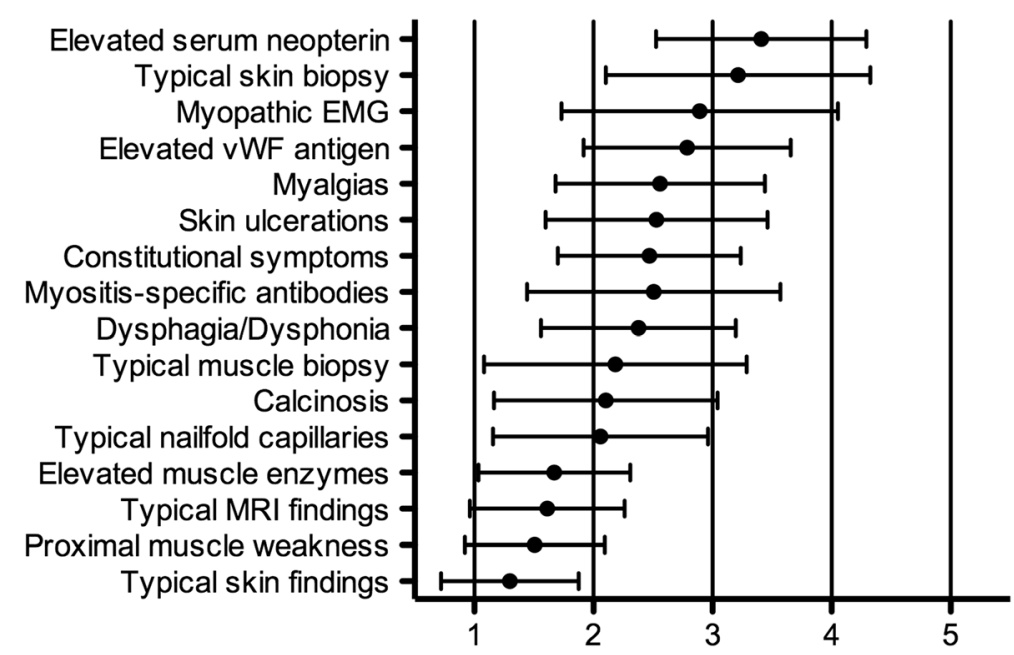

Fig. 1 Rating of various findings in establishing a diagnosis of juvenile dermatomyositis. Participants were asked to rate each individual finding in regards to its accuracy in establishing a diagnosis of juvenile dermatomyositis in clinical practice on a 5-point Likert scale $(1=$ essential, $2=$ very important, 3 = somewhat important, $4=$ not very important; $5=$ not important at all). The mean values $+/-$ standard deviation are given. Abbreviations: EMG, electromyography; MRI, magnetic resonance imaging; vWF, von Willebrand factor

assessment questionnaire (C-HAQ) (79\%), the patient/ parent global score $(76 \%)$, and the disease activity score (DAS) (70\%). Less than $50 \%$ of participants had experience in using the Pediatric Rheumatology International Trials Organization (PRINTO) core set (40\%), the Manual Muscle Testing (MMT) 8-Score (37\%), the child health questionnaire (CHQ) (36\%), the myositis damage index (MDI) (19\%) and the myositis disease activity assessment tool (MDAAT) (13\%).

\section{Initial glucocorticoid therapy in JDM}

There was marked variability in the choice of initial glucocorticoid therapy in moderate JDM (Table 2). While in moderate JDM overall $59 \%$ of participants opted for intermittent i.v. methylprednisolone pulse (IVMP) therapy, in case of severe JDM, overall $74 \%$ opted for intermittent IVMP therapy. High-dose oral therapy (here defined as prednisone equivalent $\geq 1 \mathrm{mg} / \mathrm{kg} /$ day) was chosen in case of moderate JDM by only $21 \%$, but by $40 \%$ in case of severe JDM. A large proportion of participants selected options combining intermittent IVMP therapy with either low-dose (prednisone equivalent $\leq 0.2 \mathrm{mg} / \mathrm{kg} /$ day) or moderate-dose (prednisone equivalent $>0.2$ to $<1 \mathrm{mg} / \mathrm{kg} /$ day) glucocorticoid therapy (38\% in moderate JDM and $28 \%$ in severe JDM).

\section{Strategies in glucocorticoid treatment in moderate JDM} More specific patterns on frequency and tapering were defined regarding both IVMP therapy and high-dose oral glucocorticoid therapy. This is an important issue in order to inform a future consensus process (Additional files 1 and 2). For example, the most commonly chosen options for IVMP therapy include a dose of $20 \mathrm{mg} / \mathrm{kg}$ body weight for each infusion, administration daily for 3 days every 4 weeks for 6 months. The most commonly chosen options for tapering high-dose oral glucocorticoids include initial taper after 4 weeks, a tapering interval of 4 weeks, reaching moderate-dose levels after 12 weeks, low-dose levels after 6 months and discontinuation after 12 months (Additional file 3).

Table 2 Choice of glucocorticoid regimen in moderate and severe juvenile dermatomyositis

\begin{tabular}{|c|c|c|c|c|c|c|}
\hline \multirow{3}{*}{$\begin{array}{l}\text { Oral glucocorticoid } \\
\text { therapy }\end{array}$} & \multicolumn{6}{|c|}{ Intravenous methylprednisolone pulse therapy } \\
\hline & \multicolumn{2}{|c|}{ Intermittent, ongoing } & \multicolumn{2}{|c|}{ Once at onset of therapy } & \multicolumn{2}{|l|}{ None } \\
\hline & Moderate JDM & Severe JDM & Moderate JDM & Severe JDM & Moderate JDM & Severe JDM \\
\hline High-dose $^{a}$ & $5 \%$ & $28 \%$ & $6 \%$ & $10 \%$ & $10 \%$ & $2 \%$ \\
\hline Moderate-dose $\mathrm{b}^{\mathrm{b}}$ & $19 \%$ & $23 \%$ & $19 \%$ & $8 \%$ & $0 \%$ & $0 \%$ \\
\hline Low-dose $e^{c}$ & $19 \%$ & $5 \%$ & $3 \%$ & $0 \%$ & $0 \%$ & $0 \%$ \\
\hline None & $16 \%$ & $18 \%$ & $1 \%$ & $5 \%$ & $0 \%$ & $0 \%$ \\
\hline
\end{tabular}

${ }^{a}$ prednisone equivalent of $\geq 1 \mathrm{mg} / \mathrm{kg} /$ day, ${ }^{\mathrm{b}}$ prednisone equivalent of $>0.2$ to $<1 \mathrm{mg} / \mathrm{kg} /$ day, ${ }^{\text {c }}$ prednisone equivalent $\leq 0.2 \mathrm{mg} / \mathrm{kg} / \mathrm{day}$ JDM juvenile dermatomyositis 
Choice of initial conventional disease-modifying antirheumatic drug therapy in JDM

In moderate JDM, 79\% opted for starting conventional disease-modifying antirheumatic drug (cDMARD) therapy immediately or within less than 4 weeks after overall initiation of therapy, whereas $4 \%$ opted for starting after 8 weeks and $2 \%$ for starting after 12 weeks of therapy. Sixteen \% opted for not starting any cDMARD if there was a good response to glucocorticoid therapy. Concerning the type of cDMARD chosen, $86 \%$ opted for methotrexate (MTX) (37\% for oral administration, $49 \%$ for subcutaneous administration), 21\% for hydroxychloroquin (HCQ), 9\% for azathioprin (AZA), 4\% for mycophenolate mofetil (MMF) and $1 \%$ for cyclosporin A (CSA). Assuming an adequate response to therapy, the preferred duration of MTX therapy was 12 months for $11 \%$, 24 months for 51\%, 36 months for $22 \%$ and 48 months for $2 \%$.

In severe JDM, 92\% of the experts opted for initial therapy with MTX (15\% oral, 77\% subcutaneous), 62\% for intravenous Immunoglobulins (IVIG), 56\% for HCQ, $11 \%$ for AZA, $10 \%$ for rituximab (RTX), $8 \%$ for MMF, $7 \%$ for CSA, $5 \%$ for cyclophosphamide (CYC), 3\% for TNF inhibition (TNFi) and 2\% for tocilizumab (TCZ).

\section{Management of refractory and glucocorticoid-dependent JDM}

Assuming patients had an inadequate response to therapy after 6 weeks of treatment, 73\% suggested an additional therapy, $20 \%$ a switch in therapy and $7 \%$ no change and longer observation. Of those participants choosing either additional or switch in therapy, IVIG was favored by $67 \%$, repeating or intensifying IVMP therapy by $44 \%$, CSA by $19 \%$, MMF by $14 \%$, AZA by $11 \%$, RTX by $8 \%$, TNFi by $8 \%$, CYC by $2 \%$ and TCZ by $2 \%$. Similarly, assuming a glucocorticoid-dependent disease course, i.e. increasing disease activity upon glucocorticoid tapering, 53\% suggested an additional therapy, $20 \%$ a switch in therapy and $27 \%$ a re-intensification of the current therapy. Of those participants choosing an additional or a switch in therapy options were: IVIG (79\%), MMF (35\%), CSA (31\%), AZA (24\%), RTX (21\%), TNFi (13\%), CYC (8\%) and TCZ (5\%). On a Likert scale of 1 to 5,1 indicating strong support and 5 strong rejection, the most preferred therapies in ongoing refractory moderate JDM were IVIG, MMF and RTX (Fig. 2a). In case of refractory severe JDM, the preferred options were IVIG, RTX, intensified glucocorticoid therapy and MMF (Fig. 2b). The most common IVIG dosing regimens chosen were $2 \mathrm{~g} / \mathrm{kg}$ every 4 weeks (by 56\%), $1 \mathrm{~g} / \mathrm{kg}$ every 4 weeks (by $29 \%$ ) and $2 \mathrm{~g} / \mathrm{kg}$ every 2 weeks (by 6\%). Regarding the time frame expected to observe adequate improvement in severe JDM, the most commonly named time frames were 4 weeks (by $34 \%$ ), 8 weeks by $21 \%$ and 2 weeks by $15 \%$.

\section{Discussion}

Our survey based on case scenarios of patients with typical moderate or severe JDM among pediatric rheumatologists and pediatric neurologist with an expertise in JDM demonstrates marked variability concerning strategies for the diagnosis and management of JDM in Germany. The findings deduced from these analyses will be required for the development of consensus-based treatment strategies in Germany.

An important observation is that the more than 40-year-old Bohan and Peter criteria for the diagnosis of dermatomyositis are still supported by clinical practice [4]. Most experts feel that the demonstration of typical MRI findings should become a valid criterion in the diagnosis of JDM, which is in keeping with other reports $[5,11,12]$. In addition to obtain parameters deemed
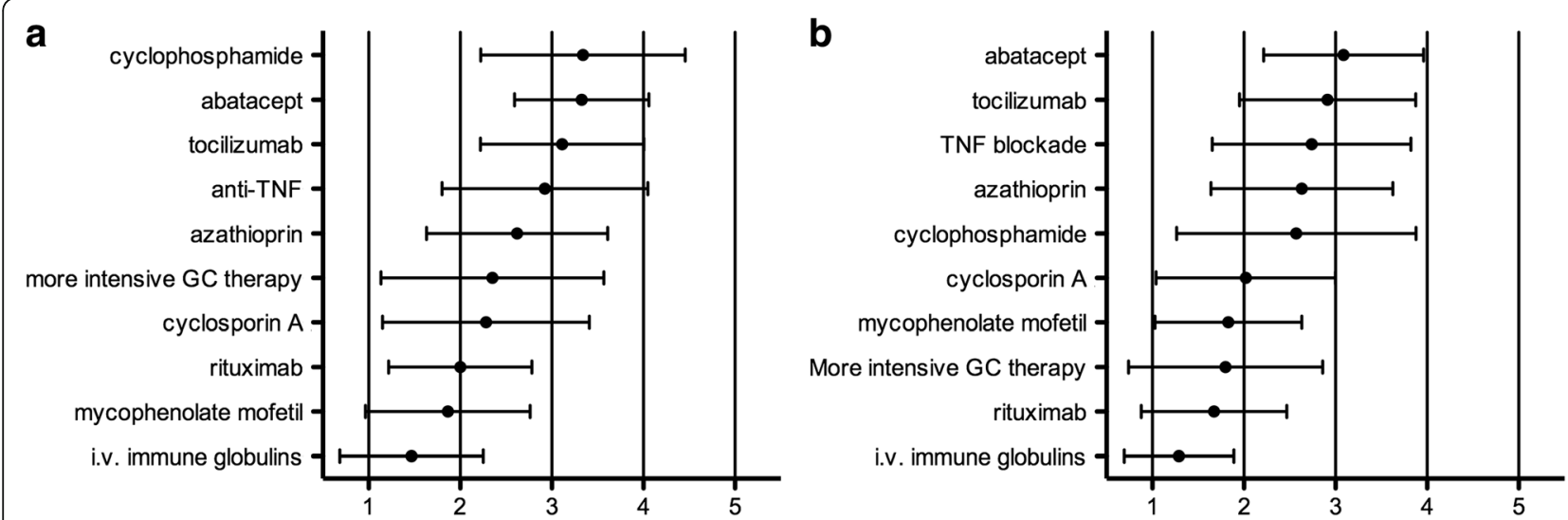

Fig. 2 Rating of various treatment options in patients with ongoing refractory (a) moderate or (b) severe juvenile dermatomyositis on a 5-point Likert scale ( 1 = support strongly, 2 = support somewhat, $3=$ neither support nor reject, $4=$ reject somewhat, $5=$ reject strongly). Mean and standard deviations are represented 
important to firmly establish the diagnosis JDM, such as MRI, muscle ultrasound, capillary microscopy and myositis-specific antibodies, several additional tests are considered to be informative in order to rule out alternative, overlapping or overarching conditions, to assess for complications of disease and to measure disease activity. As an example, these additional parameters may include serologic testing (e.g. ruling out mimicking infections), autoantibodies (e.g. ruling out lupus and related connective tissue diseases), pulmonary function testing, echocardiography, swallow studies (ruling out severe organ involvement) and/or markers of disease activity. There is evidence on the relevance of myositis-specific antibodies in regard to disease manifestations and disease course, which therefore may impact treatment decisions [13-17]. Severe organ involvement may be present even at the time of diagnosis $[18,19]$. Some organ involvement, such as cardiac involvement, may clinically not be apparent, and, thus, justify a screening strategy $[20,21]$. The ratings concerning potential markers of disease activity is controversial possibly due to the fact that many of them may be non-specific. However, von Willebrand factor antigen and serum neopterin are currently used by many German Centers [22, 23].

There is marked controversy regarding the treatment of JDM, most prominently concerning the glucocorticoid regimens used. It is well accepted that there is great variability in the use of glucocorticoids in JDM $[6,24]$. In comparison to data obtained in a similar survey by CARRA [6], in Germany, intermittent IVMP therapy is preferred much more frequently than in North America, whereas in North America high-dose oral therapy is preferred more frequently. This is also in contrast to current international consensus treatment plans, consensus recommendations and expert opinion that advocate the use of conventional high-dose oral glucocorticoid therapy $[1,7,8,25-27]$. However, some experts have advocated for the use of intermittent IVMP therapy with the goal to avoid adverse effects of glucocorticoid therapy even though some data point to the fact that IVMP therapy frequently is not sufficiently controlling disease activity [28-31]. Unfortunately, definitive data on the equivalence of conventional high-dose glucocorticoid therapy and IVMP therapy do not exist, even though a randomized trial had been initiated in Germany in the past [32].

As far as the use of additional cDMARD therapy is concerned, there is strong evidence from a rare international randomized controlled clinical trial that MTX and CSA are effective in improving control of disease activity and decreasing the cumulative glucocorticoid exposure [27]. Due to its superior adverse effects profile, the authors of that particularly study recommend methotrexate as first-line therapy over CSA.
International recommendations and protocols have firmly established MTX as a standard therapy for moderate JDM $[7,8]$. This is also reflected by current clinical practice in Germany as evidenced by this survey, similar to what has been reported in North America [6].

Substantial variability and controversy was identified regarding the treatment of JDM patients with a refractory or severe course of disease. Whereas some experts and treatment protocols place an emphasis on IVIG therapy, others, especially in the United Kingdom, commonly employ CYC therapy, a modality that is rarely used in Germany [7, 8, 33, 34]. Furthermore, while in a randomized placebo-phase controlled clinical trial in patients with refractory adult and juvenile dermatomyositis, RTX had failed to achieve the targeted primary outcome, $83 \%$ of patients in that trial achieved the definition of improvement [35]. There is evidence that the JDM subset in that trial performed better than the adult study cohort, e.g. with a two-and-a-half-fold higher chance to achieve the primary outcome [36]. There is very limited evidence for the efficacy of other cDMARDs in JDM, such as MMF [37]. For biologic DMARDS (bDMARD) like TNFi evidence on efficacy or even lack of efficacy is very limited, even though they are frequently used as outlined by a recent survey among CARRA members [38, 39]. According to our survey, there is also a strong preference for IVIG as a second-line treatment option in patients with refractory or severe JDM, with MMF and RTX both being preferred options. As expected, many practitioners also prefer the time-tested option of a higher intensity glucocorticoid therapy.

While there was substantial experience in the management of JDM, there was a relative lack of experience with formal monitoring tools, indicating that these tools have not permeated into clinical practice in Germany yet. The reason for this is unclear but it should certainly be a goal to use validated tools consistently.

There are several limitations to this work. First of all, the data presented here indicate preferences based on written case scenarios and not real patients. Therefore, these data may not necessary reflect entirely what is happening in clinical practice. Second, out of 229 members of the GKJR, only 60 participated in this survey, so that generalizability may be questioned. However, most patients with JDM are managed in larger pediatric rheumatology centers and those are reflected by our survey. Third, only 7 pediatric neurologists participated in this survey, and, therefore, practice patterns among pediatric neurologists may not be adequately represented by this survey.

\section{Conclusions}

In summary, we have established current clinical practice patterns in Germany in the diagnosis and management of 
moderate, severe, and refractory JDM based on a survey and case scenarios. Our data demonstrate substantial variability in the management of JDM but common themes emerge. Importantly, the strong preference for using an intermittent IVMP therapy in combination with low or moderate doses of glucocorticoids is in contrast to common practice and recommendations internationally. Methotrexate therapy is considered standard therapy in Germany, as it is internationally. Furthermore, IVIG, MMF and RTX is preferred by many pediatric rheumatologists in Germany in case of severe or refractory JDM. These data are helpful to inform a consensus-based process to establish harmonized strategies for the management of JDM in Germany.

\section{Additional files}

Additional file 1: Case Scenarios used in the online survey. (PDF $123 \mathrm{~kb}$ )

Additional file 2: Detailed information on patterns in the use of intravenous methylprednisolone pulse (IVMP) therapy in moderate juvenile dermatomyositis. (A) Doses employed for the individual infusions, (B) the duration of each individual therapy, (C) the overall duration of IVMP therapy and (D) the frequency of IVMP therapy. Abbreviations: IVMP intravenous methylprednisolone pulse. (JPG $273 \mathrm{~kb}$ )

Additional file 3: Detailed information on patterns in the use of high-dose glucocorticoid therapy in moderate juvenile dermatomyositis. (A) Preferred time point of initial glucocorticoid taper also in regards to the presence or absence of improvement, (B) usual interval for glucocorticoid taper, (C) preferred time point for reaching moderate-dose levels, (D) preferred time point for reaching low-dose levels and (E) preferred time point for discontinuation of glucocorticoid therapy. (JPG $374 \mathrm{~kb})$

\section{Acknowledgements}

We are grateful for the help of Jana Hörstermann with surveys and Nils Geisemeyer with data from the National Pediatric Rheumatology Database; both are from the German Rheumatism Research Centre Berlin (DRFZ). The authors thank member of the GKIR and the GNP for their participation in the survey that assessed the current clinical practice in Germany.

\section{Funding}

The publication fees were supported by the Initiative für das rheumakranke Kind (www.irkk.de), a non-for profit organization advocating for improved well-being of children with rheumatic diseases and their families, and a directed donation by the $U$ can ride for arthritis (http://www.ucanr4a.eu/en/ bicycle/) initiative.

\section{Availability of data and materials}

All data generated or analyzed during this study are included in this article.

\section{Authors' contributions}

$\mathrm{CH}$ developed the online survey, analyzed data from the survey and drafted the manuscript. FS and PO developed the online survey and revised the manuscript critically. JPH supervised the scenarios, discussed the survey's methodology and revised the manuscript. All authors are part of the PROKIND JDM project group, participated in phone conferences and online surveys, and revised the manuscript critically. All authors read and approved the final manuscript.

\section{Ethics approval and consent to participate}

Not applicable.

\section{Consent for publication}

Not applicable.

\section{Competing interests}

Dr. Hinze has received consulting fees, speaking fees, and/or honoraria from Novartis (less than $\$ 10,000$ each). Dr. Speth reports no competing interests. Dr. Oommen reports no potential competing interests. Dr. Dressler has received consulting fees, speaking fees, and/or honoraria from Novartis and Pfizer (less than $\$ 10,000$ each). Dr. Haas has received research support from Novartis and Pfizer.

\section{Publisher's Note}

Springer Nature remains neutral with regard to jurisdictional claims in published maps and institutional affiliations.

\section{Author details}

'Department of Pediatric Rheumatology and Immunology, University Hospital Münster, Albert-Schweitzer-Campus 1, Building D3, 48149 Münster, Germany. ${ }^{2}$ Division of Pediatric Rheumatology, University Medicine, Rostock, Germany. ${ }^{3}$ Division of Immunology, Bone Marrow Transplantation and Rheumatology, Ulm, Germany. ${ }^{4}$ Center of Child and Adolescent Health, Department of Pediatric Oncology, Hematology and Clinical Immunology, Heinrich-Heine University Duesseldorf, Münster, Germany. ${ }^{5}$ German Center for Pediatric and Adolescent Rheumatology, Garmisch-Partenkirchen, Germany.

Received: 28 February 2018 Accepted: 12 June 2018

Published online: 20 June 2018

References

1. Feldman BM, Rider LG, Reed AM, Pachman LM. Juvenile dermatomyositis and other idiopathic inflammatory myopathies of childhood. Lancet. 2008; 371(9631):2201-12.

2. Dressler F, Frosch M, Monkemoller K, Thon A, Weissbarth-Riedel E, Horneff $\mathrm{G}$. Results of the German ESPED-recording of new patients with juvenile dermatomyositis (JDM). Klin Padiatr. 2011;223(5):280-2.

3. Ravelli A, Trail L, Ferrari C, Ruperto N, Pistorio A, Pilkington C, Maillard S, Oliveira SK, Sztajnbok F, Cuttica R, et al. Long-term outcome and prognostic factors of juvenile dermatomyositis: a multinational, multicenter study of 490 patients. Arthritis Care Res (Hoboken). 2010;62(1):63-72.

4. Bohan A, Peter JB. Polymyositis and dermatomyositis (first of two parts). N Engl J Med. 1975;292(7):344-7.

5. Brown VE, Pilkington CA, Feldman BM, Davidson JE. Network for juvenile dermatomyositis PRES: an international consensus survey of the diagnostic criteria for juvenile dermatomyositis (JDM). Rheumatology (Oxford). 2006; 45(8):990-3.

6. Stringer E, Bohnsack J, Bowyer SL, Griffin TA, Huber AM, Lang B, Lindsley CB, Ota S, Pilkington C, Reed AM, et al. Treatment approaches to juvenile dermatomyositis (JDM) across North America: the childhood arthritis and rheumatology research alliance (CARRA) JDM treatment survey. J Rheumatol. 2010:37(9):1953-61.

7. Enders FB, Bader-Meunier B, Baildam E, Constantin T, Dolezalova P, Feldman BM, Lahdenne P, Magnusson B, Nistala K, Ozen S, et al. Consensus-based recommendations for the management of juvenile dermatomyositis. Ann Rheum Dis. 2017;76(2):329-40.

8. Huber AM, Robinson AB, Reed AM, Abramson L, Bout-Tabaku S, Carrasco R, Curran M, Feldman BM, Gewanter H, Griffin T, et al. Consensus treatments for moderate juvenile dermatomyositis: beyond the first two months. Results of the second childhood arthritis and rheumatology research alliance consensus conference. Arthritis Care Res (Hoboken). 2012;64(4):546-53.

9. Lilleker JB, Vencovsky J, Wang G, Wedderburn LR, Diederichsen LP, Schmidt J, Oakley P, Benveniste O, Danieli MG, Danko K, et al. The EuroMyositis registry: an international collaborative tool to facilitate myositis research. Ann Rheum Dis. 2018;77(1):30-9.

10. Martin N, Krol P, Smith S, Murray K, Pilkington CA, Davidson JE, Wedderburn $L R$, Juvenile Dermatomyositis Research G. A national registry for juvenile dermatomyositis and other paediatric idiopathic inflammatory myopathies: 10 years' experience; the juvenile dermatomyositis national (UK and Ireland) cohort biomarker study and repository for idiopathic inflammatory myopathies. Rheumatology (Oxford). 2011;50(1):137-45.

11. Malattia C, Damasio MB, Madeo A, Pistorio A, Providenti A, Pederzoli S, Viola S, Buoncompagni A, Mattiuz C, Beltramo A, et al. Whole-body MRI in the assessment of disease activity in juvenile dermatomyositis. Ann Rheum Dis. 2014;73(6):1083-90. 
12. Ladd PE, Emery KH, Salisbury SR, Laor T, Lovell DJ, Bove KE. Juvenile dermatomyositis: correlation of MRI at presentation with clinical outcome. AJR Am J Roentgenol. 2011;197(1):W153-8.

13. Rider LG, Shah M, Mamyrova G, Huber AM, Rice MM, Targoff IN, Miller FW. The myositis autoantibody phenotypes of the juvenile idiopathic inflammatory myopathies. Medicine (Baltimore). 2013;92(4):223-43.

14. Rider LG, Nistala K. The juvenile idiopathic inflammatory myopathies: pathogenesis, clinical and autoantibody phenotypes, and outcomes. J Intern Med. 2016;280(1):24-38.

15. Kishi T, Rider LG, Pak K, Barillas-Arias L, Henrickson M, McCarthy PL, Shaham B, Weiss PF, Horkayne-Szakaly I, Targoff IN, et al. Association of Anti-3Hydroxy-3-Methylglutaryl-coenzyme a reductase autoantibodies with DRB1*07:01 and severe myositis in juvenile myositis patients. Arthritis Care Res (Hoboken). 2017;69(7):1088-94.

16. Gunawardena H, Wedderburn LR, North J, Betteridge Z, Dunphy J, Chinoy H, Davidson JE, Cooper RG, McHugh NJ. Clinical associations of autoantibodies to a p155/140 kDa doublet protein in juvenile dermatomyositis. Rheumatology (Oxford). 2008;47(3):324-8.

17. Deakin CT, Yasin SA, Simou S, Arnold KA, Tansley SL, Betteridge ZE, McHugh $N J$, Varsani $H$, Holton $J L$, Jacques TS, et al. Muscle biopsy findings in combination with myositis-specific autoantibodies aid prediction of outcomes in juvenile dermatomyositis. Arthritis \& rheumatology. 2016; 68(11):2806-16

18. McCann $\amalg$, Juggins AD, Maillard SM, Wedderburn LR, Davidson JE, Murray KJ, Pilkington CA, Juvenile Dermatomyositis Research G. The juvenile dermatomyositis National Registry and repository (UK and Ireland)-clinical characteristics of children recruited within the first $5 \mathrm{yr}$. Rheumatology (Oxford). 2006;45(10):1255-60.

19. Pachman LM, Hayford JR, Chung A, Daugherty CA, Pallansch MA, Fink CW, Gewanter $\mathrm{HL}$, Jerath $\mathrm{R}$, Lang BA, Sinacore J, et al. Juvenile dermatomyositis at diagnosis: clinical characteristics of 79 children. J Rheumatol. 1998;25(6): 1198-204.

20. Schwartz T, Sanner H, Husebye T, Flato B, Sjaastad I. Cardiac dysfunction in juvenile dermatomyositis: a case-control study. Ann Rheum Dis. 2011;70(5): 766-71

21. Cantez S, Gross GJ, MacLusky I, Feldman BM. Cardiac findings in children with juvenile dermatomyositis at disease presentation. Pediatr Rheumatol Online J. 2017;15(1):54.

22. Guzman J, Petty RE, Malleson PN. Monitoring disease activity in juvenile dermatomyositis: the role of von Willebrand factor and muscle enzymes. J Rheumatol. 1994;21(4):739-43.

23. De Benedetti F, De Amici M, Aramini L, Ruperto N, Martini A. Correlation of serum neopterin concentrations with disease activity in juvenile dermatomyositis. Arch Dis Child. 1993;69(2):232-5.

24. Hasija R, Pistorio A, Ravelli A, Demirkaya E, Khubchandani R, Guseinova D, Malattia C, Canhao H, Harel L, Foell D, et al. Therapeutic approaches in the treatment of juvenile dermatomyositis in patients with recent-onset disease and in those experiencing disease flare: an international multicenter PRINTO study. Arthritis Rheum. 2011:63(10):3142-52.

25. Kim S, El-Hallak M, Dedeoglu F, Zurakowski D, Fuhlbrigge RC, Sundel RP. Complete and sustained remission of juvenile dermatomyositis resulting from aggressive treatment. Arthritis Rheum. 2009;60(6):1825-30.

26. Robinson $A B$, Reed AM. Clinical features, pathogenesis and treatment of juvenile and adult dermatomyositis. Nat Rev Rheumatol. 2011;7(11):664-75

27. Ruperto N, Pistorio A, Oliveira S, Zulian F, Cuttica R, Ravelli A, Fischbach M, Magnusson B, Sterba G, Avcin T, et al. Prednisone versus prednisone plus ciclosporin versus prednisone plus methotrexate in new-onset juvenile dermatomyositis: a randomised trial. Lancet. 2016;387(10019):671-8.

28. Dressler F, Huppertz HI. Juvenile dermatomyositis. Z Rheumatol. 2006;65(7): 587-90. 592-584

29. Rouster-Stevens KA, Gursahaney A, Ngai KL, Daru JA, Pachman LM. Pharmacokinetic study of oral prednisolone compared with intravenous methylprednisolone in patients with juvenile dermatomyositis. Arthritis Rheum. 2008:59(2):222-6.

30. Laxer RM, Stein LD, Petty RE. Intravenous pulse methylprednisolone treatment of juvenile dermatomyositis. Arthritis Rheum. 1987;30(3):328-34.

31. Lang B, Dooley J. Failure of pulse intravenous methylprednisolone treatment in juvenile dermatomyositis. J Pediatr. 1996:128(3):429-32.

32. Huppertz HI, Frosch M, Kuhn C, Christen HJ. Treatment of juvenile dermatomyositis (JDM) with highdose oral steroids or with steroid pulse therapy. Arthritis Rheum. 1998;41(9 Suppl):S264.
33. Lam CG, Manlhiot C, Pullenayegum EM, Feldman BM. Efficacy of intravenous Ig therapy in juvenile dermatomyositis. Ann Rheum Dis. 2011:70(12):2089-94.

34. Riley P, Maillard SM, Wedderburn LR, Woo P, Murray KJ, Pilkington CA. Intravenous cyclophosphamide pulse therapy in juvenile dermatomyositis. A review of efficacy and safety. Rheumatology (Oxford). 2004;43(4):491-6.

35. Oddis CV, Reed AM, Aggarwal R, Rider LG, Ascherman DP, Levesque MC, Barohn RJ, Feldman BM, Harris-Love MO, Koontz DC, et al. Rituximab in the treatment of refractory adult and juvenile dermatomyositis and adult polymyositis: a randomized, placebo-phase trial. Arthritis Rheum. 2013;65(2): 314-24.

36. Aggarwal R, Bandos A, Reed AM, Ascherman DP, Barohn RJ, Feldman BM, Miller FW, Rider LG, Harris-Love MO, Levesque MC, et al. Predictors of clinical improvement in rituximab-treated refractory adult and juvenile dermatomyositis and adult polymyositis. Arthritis \& rheumatology. 2014; 66(3):740-9.

37. Rouster-Stevens KA, Morgan GA, Wang D, Pachman LM. Mycophenolate mofetil: a possible therapeutic agent for children with juvenile dermatomyositis. Arthritis Care Res (Hoboken). 2010;62(10):1446-51.

38. Rouster-Stevens KA, Ferguson L, Morgan G, Huang CC, Pachman LM. Pilot study of etanercept in patients with refractory juvenile dermatomyositis. Arthritis Care Res (Hoboken). 2014;66(5):783-7.

39. Spencer $\mathrm{CH}$, Rouster-Stevens $\mathrm{K}$, Gewanter $\mathrm{H}$, Syverson $\mathrm{G}$, Modica $\mathrm{R}$, Schmidt K, Emery H, Wallace C, Grevich S, Nanda K, Zhao YD, Shenoi S, Tarvin S, Hong S, Lindsley C, Weiss JE, Passo M, Ede K, Brown A, Ardalan K, Bernal W, Stoll ML, Lang B, Carrasco R, Agaiar C, Feller L, Bukulmez H, Vehe R, Kim H, Schmeling H, Gerstbacher D, Hoeltzel M, Eberhard B, Sundel R, Kim S, Huber AM, Patwardhan A. Biologic therapies for refractory juvenile dermatomyositis: five years of experience of the Childhood Arthritis and Rheumatology Research Alliance in North America. Pediatr Rheumatol. 2017; 15(1):50. https://doi.org/10.1186/s12969-017-0174-0.

Ready to submit your research? Choose BMC and benefit from

- fast, convenient online submission

- thorough peer review by experienced researchers in your field

- rapid publication on acceptance

- support for research data, including large and complex data types

- gold Open Access which fosters wider collaboration and increased citations

- maximum visibility for your research: over $100 \mathrm{M}$ website views per year

At BMC, research is always in progress.

Learn more biomedcentral.com/submissions 